TI 2000-060/3

Tinbergen Institute Discussion Paper

\title{
A Meta-Analysis of Price Elasticities of Transport Demand in a General Equilibrium Framework
}

Hans Kremers

Peter Nijkamp

Piet Rietveld 
Tinbergen Institute

The Tinbergen Institute is the institute for economic research of the Erasmus Universiteit Rotterdam, Universiteit van Amsterdam and

Vrije Universiteit Amsterdam.

Tinbergen I nstitute Amsterdam

Keizersgracht 482

1017 EG Amsterdam

The Netherlands

Tel.: +31.(0)20.5513500

Fax: $\quad+31 .(0) 20.5513555$

Tinbergen I nstitute Rotterdam

Burg. Oudlaan 50

3062 PA Rotterdam

The Netherlands

Tel.: $\quad+31 .(0) 10.4088900$

Fax: $\quad+31 .(0) 10.4089031$

Most TI discussion papers can be downloaded at

http://www.tinbergen.nl 


\title{
A Meta-Analysis \\ of \\ Price Elasticities \\ of \\ Transport Demand \\ in a \\ General Equilibrium Framework
}

\author{
Hans Kremers \\ Peter Nijkamp \\ Piet Rietveld
}

\author{
MASTER-POINT \\ Department of Spatial Economics \\ Free University \\ De Boelelaan 1105 \\ NL-1081 HV Amsterdam \\ The Netherlands
}

31 May 2000

\begin{abstract}
Price elasticities of transport demand are an important tool to assess the impacts of pricing policies. Empirical research on these elasticities leads to a rather wide range of outcomes. There is obviously a need for a more rigorous methodological framework. This paper provides a new integrative approach to the estimation of price elasticities while taking into account any combination of characteristics of transport demand found in various empirical studies. To this end, we apply metaanalysis to this set of studies. From the various modelling approaches that underly these studies we develop an overlapping general equilibrium framework that provides a meta-regression equation relating the price elasticity estimate to the study characteristics.
\end{abstract}




\section{Introduction}

The last decades have witnessed an explosive growth in the demand for transport all over the world following an increase in economic activities in the EU, the USA, and Asian countries like Japan and Korea. Statistics show a structural rise in mobility of travelers, while the liberalisation of trade world-wide (WTO) and in the EU has caused a drastic increase in transboundary freight transport (see for figures Reggiani et al. (1999). There is apparently no natural limit to the rise in physical movements of people and commodities. Both locally and globally transport is on a rising edge. This explosive growth in transport has clearly an important environmental impact in the form of heavily increased pollution, more accidents, noise, and congestion, causing national as well as international governmental bodies to worry about the sustainability of their transport systems (see for an overview Nijkamp and Pepping (1998)).

In many cases transport is not an aim itself, but it derives its value from other production of consumption aims. Therefore, it is plausible to assume that the increase in economic activities causes an increased transport demand. The prices of transport modes tend not to reflect their true costs they inflict on society, because environmental costs are not accounted for. These costs are not equal for all transport modes, and hence the distribution of demand for transport over the different modes is not efficient from a societal viewpoint. Governments are therefore trying to include the environmental costs of each transport mode into its price hoping to obtain a more efficient distribution of transport demand over the various transport modes. This redistribution of transport demand may then lead to a substantial decrease in the environmental impact of the country's transport system.

'Fair pricing' has become even a policy objective with a view to a better incorporation of externalities in transport policy. Nijkamp and Pepping (1998) mention the price elasticity of transport demand as the most important parameter to understand how pricing policies will affect transport demand. This price elasticity is defined as the relative change in demand for a given mode induced by a relative change in price.

It is no surprise that in the last few years several studies in European countries have assessed price elasticities of demand in the transport sector, which has led to a great diversity of empirical results. Nijkamp and Pepping (1998) mention that most of these investigations have been made on a non-controlled basis, resulting in a rather feeble comparability of the results from these studies. The well-known survey of Oum, Waters II, and Yong (1992) argues even that across-the-board generalizations about transport demand are impossible. Competition between modes, routes or firms and site-specific conditions give rise to a wide range of price elasticities. Factors such as the time horizon, the degree of aggregation, the functional specification and the like, used in these studies turn out to have a significant bearing 
on the elasticity estimates.

Despite the variety in background in these elasticity estimates, Nijkamp and Pepping (1998) consider it sensible to analyze the differences in statistical results in order to identify commonalities and site-specific differences more precisely, as it would allow for more transferability of results under varying quasi-experimental conditions. In their view meta-analysis may play an important role in this framework. The authors carry out a comparative analysis of different elasticity values of demand for transport that are being used in various member states of the European Union. Their comparative analysis is based on a recently developed approach called rough set analysis.

Meta-analysis has originally been developed as a tool for comparing and synthesizing results from different studies in the natural sciences and has in the past decade also become popular in experimental psychology and medicine. Behavioural studies in these sciences tend to be more similar and they often consist of comparing the results from experiments. This semi-controlled experimentation leads to a similarity in studies which is then lost in the economic sciences due to the existence of the ceteris-paribus condition as argued in Bal and Nijkamp (1999). This applies in particular to the assessment of price-elasticities in transport due to the factors already mentioned in Oum, Waters II, and Yong (1992). A meta-analysis of studies that assess the value of price-elasticities of transport demand should take into account the different underlying data and the behavioural models pertaining to transport. The question is now whether it is possible to develop a common frame of reference (or a benchmark) to compare different elasticity studies.

Kremers, Nijkamp, and Rietveld (1999) suggest that a general equilibrium model including transport and its impact on the environment can serve as an encapsulating model for a meta-analysis in the field of transport policy analysis in relation to environmental economics. Following their approach we aim to present here a general equilibrium model that is able to encapsulate in principle the various price elasticity studies. It is the controlled basis necessary for comparing the studies by providing a framework in the form of an 'envelope' model. Such a model is then also able to offer the foundation for an empirical estimation of price elasticities in the transport sector.

The next section describes the general equilibrium model framework that is thought to act as an envelope for the models in the various studies underlying a meta-analysis of price elasticities of transport demand. In the succeeding section, this framework is used to derive the common characteristics of these models, which are of influence on the estimation of a price elasticity of transport demand. We concentrate our meta-analysis on own-price elasticities. The main result of this section is a set of regression equations that link the various price elasticities of transport demand to these common characteristics. This set of regression equations then form the analytical basis of the actual empirical meta-analysis applied in Section 4. 


\section{An Encapsulating General Equilibrium Model}

In our search for a common reference model for elasticity estimates, we introduce a general equilibrium model that is assumed to encapsulate all the models used in the different studies that underly a meta-analysis of price elasticities of transport demand. We provide a specification of the model to give an example. The studies in our meta-analysis may use a different specification. This general equilibrium model is such that it contains all characteristics of the individual studies in the meta-analysis concerned. Furthermore, this general equilibrium model serves to provide us with an appropriate conceptual framework within which we can consider the determination of transport demand elasticities.

The majority of elasticity studies covers public transport. Therefore, we will mainly address modal choice in transport with a view to public transport and hence focus on a national transport system.

The studies in our meta-analysis mainly focus on the transport sector. We construct the transport sector of the general equilibrium model framework from the transport models in the various studies. Transport can be considered from the most aggregate level as one good to its most disaggregate level, for example by bus or by train. This paper takes transport as determined by its underlying infrastructure, e.g. road, rail, and air, as the most disaggregate level. A transport mode $t$ consists of an industry that produces the required amount of transport, and an underlying infrastructure given by $I_{t}$ that we consider as given.

The transport sector in the economy is represented by the transport tree $\mathcal{T}$ whose top is depicted in Figure 1 . Let $\mathcal{T}=\left(W_{\mathcal{T}}, A_{\mathcal{T}}\right)$, where $W_{\mathcal{T}}$ is the set of nodes in the tree $\mathcal{T}$ and $A_{\mathcal{T}}$ the set of arcs that connect these nodes. A tree consists of layers, where the top is assumed to fall in layer 0 of the tree. It is directed from the top along the arcs towards the nodes in the lowest level. We can define a mapping on the tree $\mathcal{T}$ where each component has a superindex referring to the layer of the tree it refers to, and a sequence of subindices referring to the predecessors of the current node. Let $w_{\mathcal{T}}^{k} \in W_{\mathcal{T}}$ denote the ordered set that represents a node in $\mathcal{T}$ and $w_{\mathcal{T}}^{k}(h)$ its $h$-th component. For example, node $(11)=w_{\mathcal{T}}^{2}$ represents ordinary fare transport with $w_{\mathcal{T}}^{2}(1)=1$ and $w_{\mathcal{T}}^{2}(2)=1$. There exists a top node, $w_{\mathcal{T}}^{0}$, in $A_{\mathcal{T}}$ referred to as the root of the tree. Let $\left|W_{\mathcal{T}}\right|$ denote the number of nodes in the tree $\mathcal{T}$.

The root of $\mathcal{T}$ contains transport as a composite good. Transport is decomposed according to the underlying market type into transport sectors that set the price and transport sectors that take the price as given, in the first layer of $\mathcal{T}$. In the second layer of the transport tree, the transport sectors charge an ordinary fare or provide the possibility of a farecard, following Henscher (1998) and Gilbert and Jalilian (1991). This brings us to Figure 1 as the top of the transport tree $\mathcal{T}$. 


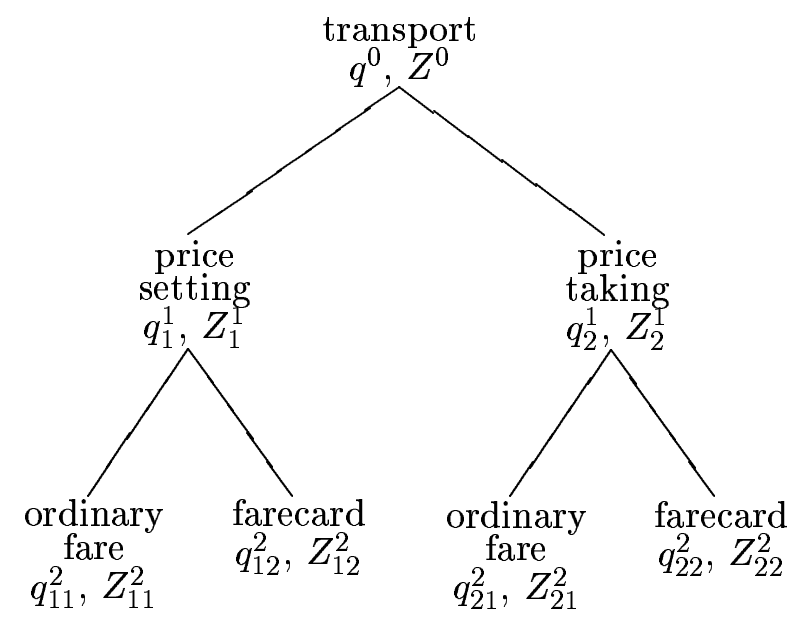

FiguRE 1: The top of the transport tree $\mathcal{T}$; the transport supply in each node is given by a mapping $Z: W_{\mathcal{T}} \rightarrow \mathbf{R}_{+}^{\left|W_{\mathcal{T}}\right|}$, the prices of each transport type are given by a mapping $q: W_{\mathcal{T}} \rightarrow \mathbb{R}_{+}^{\left|W_{\mathcal{T}}\right|}$.

Figure 2 decomposes ordinary fare and farecard transport with respect to each market type further into road, air, and rail transport, each referring to an infrastructure with a capacity of respectively $I_{1}, I_{2}$, and $I_{3}$ volume units during a certain time period. We omit transport by water as we have not obtained studies on this field. The infrastructure is used by both price setting and price taking transport sectors. In line with common practice in applications of discrete choice analysis in this field, we also distinguish a set of attributes denoted by a subindexed set $A$ with each transport sector. Such a set contains the attributes like for example, the door-to-door travel time of each transport mode as referred to in Henscher (1998).

Figures 1 and 2 also provides the supply of each type of transport by a mapping $Z$ on $\mathcal{T}$. The output of each transport sector $w_{\mathcal{T}}^{3}$ can then be denoted by $Z_{w_{\mathcal{T}}^{3}}^{3}$ in layer 3 of the transport tree $\mathcal{T}$. For example, $Z_{111}^{3}$ denotes the output of the road transport sector setting ordinary fares, while $Z_{211}^{3}$ denotes the output of price taking road transport. $Z_{t}$ volume units of transport mode $t$ are produced from $l_{t}$ hours of labour, $k_{t}$ units of capital, $e_{t}$ units of energy, and $a_{t}$ units of infrastructure, according to a production function $g_{t}$ that exhibits constant returns to scale,

$$
Z_{t}=g_{t}\left(l_{t}, k_{t}, e_{t}, a_{t}\right)
$$

The output of transport sector $t$ should be such that $Z_{t}=\sum_{\left(w_{\mathcal{T}}^{2}, t\right) \in W_{t}} Z_{\left(w_{\mathcal{T}}^{2}, t\right) \in W_{t}}^{3}$. Cost minimization results into the labour, capital, energy, and infrastructure input demand functions per volume unit of output for each transport mode $t$. 


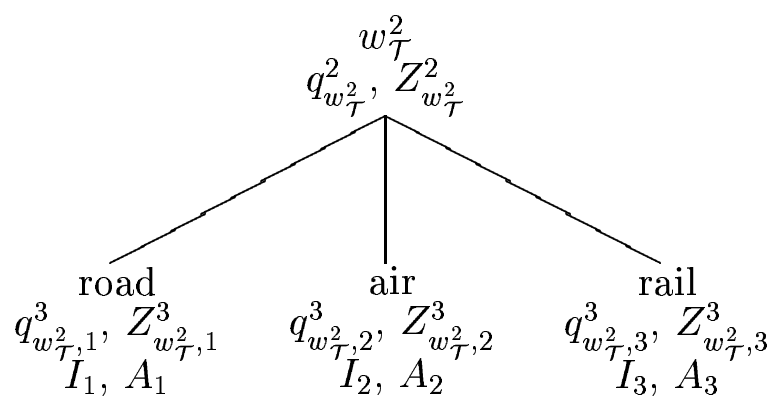

Figure 2: The subtree of $\mathcal{T}$ related to $w_{\mathcal{T}}^{2}$; The subindexed number $I$ denotes the capacity of the infrastructure in volume units during a certain time interval, and the subindexed set $A$ denotes the set of attributes associated with each transport sector.

The constant returns to scale assumption that underlies the production technology of each transport sector implies that the output levels of the transport sectors are demand determined. When the output levels of these transport sectors are determined, then we can construct the supply levels in the preceding layer of the transport tree $\mathcal{T}$ by using the output levels of these transport sectors as an input into a Leontief type production technology. Proceeding upwards in $\mathcal{T}$ in this way we can use a Leontief type production technology to determine the levels of the output mapping $Z$.

We consider transport demand as derived from the economic activities of the consumers and producers. These economic activities consist of the production and consumption of goods, and the supply and demand of capital and labour in a country that consists of regions $1, \ldots, J$. Each region consists of a representative consumer and a representative producer that can be seen as the aggregation over all individual consumers and producers respectively. The producer produces the region's commodity, which is a composite of all the commodities in this region. His production technology uses the commodities of other regions as intermediate inputs, and labour and capital from the country's labour and capital markets as primary inputs.

Given wage rate $w$ and interest rate $r$, consumer $j$ obtains an income $M=r K+w \Lambda$ from supplying his initial endowment of capital $K$ to the capital market and $\Lambda$ hours of labour to the labour market. According to the first layer in the consumption tree $\mathcal{C}$ of the consumer depicted in Figure 3, this income is spent on economic activities $\mathrm{EA}^{C}$ and on transport $x^{C}$ to perform these activities. 


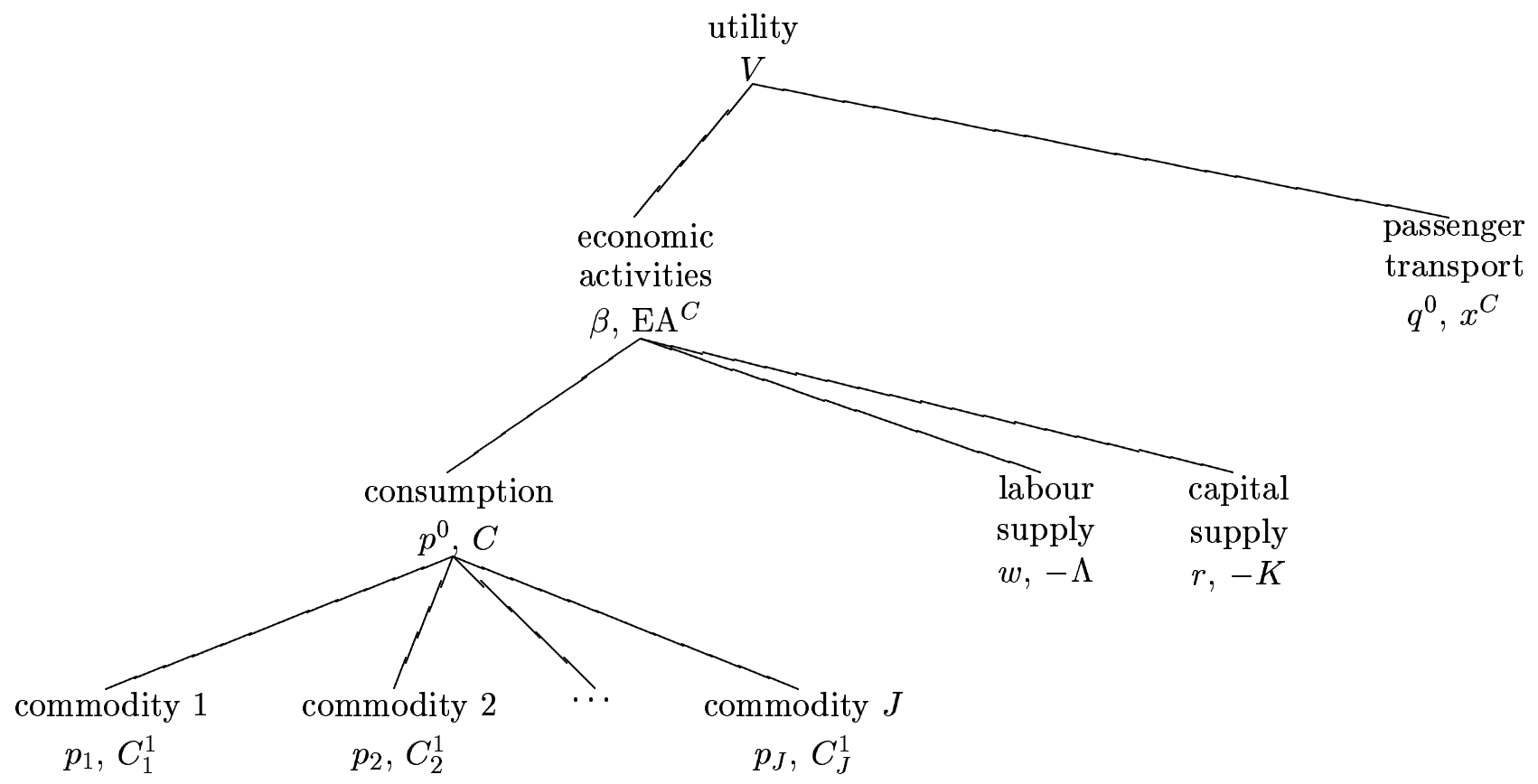

Figure 3: The consumption tree $\mathcal{C}=\left(W_{\mathcal{C}}, A_{\mathcal{C}}\right)$ of a consumer, where each node provides the utility maximizing quantity of each good, and its price.

Under the assumption of utility maximization, the consumer obtains an indirect utility $V\left(\beta, q^{0}, w\right)$ by solving the optimization problem

$$
\begin{array}{lll}
V\left(\beta, q^{0} ; M\right)=\max _{\mathrm{EA}^{C}, x^{C, 0}} & \min \left\{\frac{\mathrm{EA}^{C}}{\gamma_{1}^{1}}, \frac{x^{C, 0}}{\gamma_{j}^{1}}\right\} \\
\text { s.t. } & \beta \mathrm{EA}^{C}+q^{0} x^{C, 0} \leq M \\
& \mathrm{EA}^{C} \geq 0, x^{C, 0} \geq 0,
\end{array}
$$

where $\beta$ denotes the price of economic activities. We define a mapping $\gamma^{C}: A_{\mathcal{C}} \rightarrow[0,1]^{\left|A_{\mathcal{C}}\right|}$ of share parameters over $\mathcal{C}$. Optimization problem (2) results in the consumer's optimal amount of economic activities and the optimal amount of transport necessary to perform them.

Passenger transport is constructed similarly to figures 1 and 2 . The transport tree $\mathcal{T}$ is attached to the consumption tree $\mathcal{C}$ of the consumer by taking $x^{C, 0}$ as its root. This results in a transport demand mapping $x^{C}: W_{\mathcal{T}} \rightarrow \mathbb{R}_{+}^{\left|W_{\mathcal{T}}\right|}$.

The aggregate good transport in optimization problem (1) can be decomposed into the available transport alternatives on any layer $k$ of transport tree $\mathcal{T}$, according to a constant elasticity of substitution type utility function. This provides the following optimization problem, 


$$
\begin{array}{ll}
\max _{x^{C, k}} & \left(\sum_{w_{\mathcal{T}}^{k} \in W_{\mathcal{T}}}\left(x_{w_{\mathcal{T}}^{k}}^{C, k}\right)^{\rho^{k}}\right)^{\frac{1}{\rho^{k}}} \\
\text { s.t. } & \sum_{w_{\mathcal{T}}^{k} \in W_{\mathcal{T}}} q_{w_{\mathcal{T}}^{k}}^{k} x_{w_{\mathcal{T}}^{k}}^{C, k}=q^{0} x^{C, 0} .
\end{array}
$$

Anas and Moses (1984), Henscher (1998), and Taplin (1997) use discrete choice analysis to model individual consumer behaviour with respect to different transport alternatives. BenAkiva and Lerman (1987) provide an often referred to overview on this subject. According to discrete choice analysis studies, the individual consumer's preferences are given by a utility function which, according to random utility theory, consists of a quantifiable proportion and random or unobservable effects. Discrete choice analysis lets the consumer choose one type of transport $w_{\mathcal{T}}^{k} \in W_{\mathcal{T}}$ with a certain probability $\pi_{w_{\mathcal{T}}^{k}}^{C}$.

Let a region consist of $N$ statistically identical and independent individual consumers. Then Anderson, de Palma, and Thisse (1992) prove that the representative consumer of this region whose choices among the available transport alternatives on any layer $k$ of the transport tree $\mathcal{T}$ are modelled by optimization problem (2) is equivalent to $N$ individual consumers in this region, each of them choosing transport alternative $w_{\mathcal{T}}^{k}$ with a probability $\pi_{w_{\mathcal{T}}^{k}}^{C}$ given by the multinomial logit model

$$
\pi_{w_{\mathcal{T}}^{k}}^{C}=\frac{\exp \left[v\left(q_{w_{\mathcal{T}}^{k}}^{k} ; q^{0} x^{C, 0}\right)\right]}{\sum_{\hat{w}_{\mathcal{T}}^{k} \in W_{\mathcal{T}}} \exp \left[v\left(q_{\hat{w}_{\mathcal{T}}^{k}}^{k} ; q^{0} x^{C, 0}\right)\right]}
$$

where

$$
v\left(q_{w_{\mathcal{T}}^{k}}^{k} ; q^{0} x^{C, 0}\right)=\left(\frac{\rho^{k}}{1-\rho^{k}}\right)\left(-\ln q_{w_{\mathcal{T}}^{k}}^{k}+\ln q^{0} x^{C, 0}\right) .
$$

More generally, the discrete choice studies in our meta-analysis also consider the influence of a transport mode $t$ 's characteristics denoted by the set $A_{t}$. This requires a generalization of (2) to include these characteristics, while $\pi_{w_{\mathcal{T}}^{k}}^{C}$ and $v$ become $\pi_{w_{\mathcal{T}}^{k}}^{C}\left(q_{w_{\mathcal{T}}^{k}}^{k} ; A_{w_{\mathcal{T}}^{k}}\right)$ and $v\left(q_{w_{\mathcal{T}}^{k}}^{k} ; q^{0} x^{C, 0}, A_{w_{\mathcal{T}}^{k}}\right)$. The probability density function that underlies $\pi^{C}$ are defined in Henscher (1998) and Bhat (1995) using a so-called Type I Extreme Value density function $f(t)=\exp (-t) \exp [-\exp (t)]$, while Anas and Moses (1984) also use a probit model.

Figure 3 decomposes the economic activities of the consumer into consumption $C$, labour supply $\Lambda$, and capital supply $K$. We take $L$ to be the total time endowment of the consumer to be allocated between labour time $\Lambda$ and free time $L-\Lambda$. He only obtains utility from $L-\Lambda$. 
The utility maximizing amounts of these entities can be obtained from the maximization problem

$$
\begin{array}{ll}
\max _{C, \Lambda, K} & \mathrm{EA}^{C}=\left(\gamma_{11}^{C, 2} C^{\frac{\delta_{2}^{C}-1}{\delta_{2}^{C}}}+\gamma_{12}^{C, 2}(L-\Lambda)^{\frac{\delta_{2}^{C}-1}{\delta_{2}^{C}}}\right)^{\frac{\delta_{2}^{C}}{\delta_{2}^{C}-1}} \\
\text { s.t. } & p^{0} C=w \Lambda+r K+\beta \mathrm{EA}^{C} \\
& C \geq 0, \Lambda \geq 0, K \geq 0,
\end{array}
$$

where we have used a constant elasticity of substitution function with substitution elasticity $\delta_{2}^{C}$ between the consumer's consumption and his labour supply.

The consumption good is an aggregate of the $J$ goods of the country. In the previous optimization problem, this aggregate consumption good has a price $p^{0}$. The optimal amounts of each region's commodity in the last layer of the consumption tree $\mathcal{C}$, that constitute this aggregate consumption good, can be obtained from the utility maximization problem

$$
\begin{array}{ll}
\max _{C_{1}, \ldots, C_{J}} & C=\left(\sum_{h=1}^{J} \gamma_{11 h}^{C, 3} C_{h}^{\frac{\delta_{3}^{C}-1}{\delta_{3}^{C}}}\right)^{\frac{\delta_{3}^{C}}{\delta_{3}^{C}-1}} \\
\text { s.t. } & \sum_{h=1}^{J} p_{h} C_{h}=p^{0} C \\
& C_{1} \geq 0, \ldots, C_{J} \geq 0,
\end{array}
$$

where we have used a constant elasticity of substitution function with a substitution elasticity of $\delta_{3}^{C}$ among the different consumption goods, to obtain the consumer's optimal consumption.

The producer produces the region's composite commodity using the other region's commodities as intermediates, and hours of labour and units of capital as primary inputs. Figure 4 provides the production tree $\mathcal{P}=\left(W_{\mathcal{P}}, A_{\mathcal{P}}\right)$ for a producer.

The production technology of the producer in the first layer of $\mathcal{P}$ is given by a constant returns to scale function which transforms his economic activities, $\mathrm{EA}^{P}$, and the amount of freight transport necessary to perform these activities, $x^{P, 0}$, into $Y$ units of the region's commodity,

$$
Y=\min \left\{\frac{\mathrm{EA}^{P}}{\gamma_{1}^{P, 1}}, \frac{x^{P, 0}}{\gamma_{2}^{P, 1}}\right\}
$$




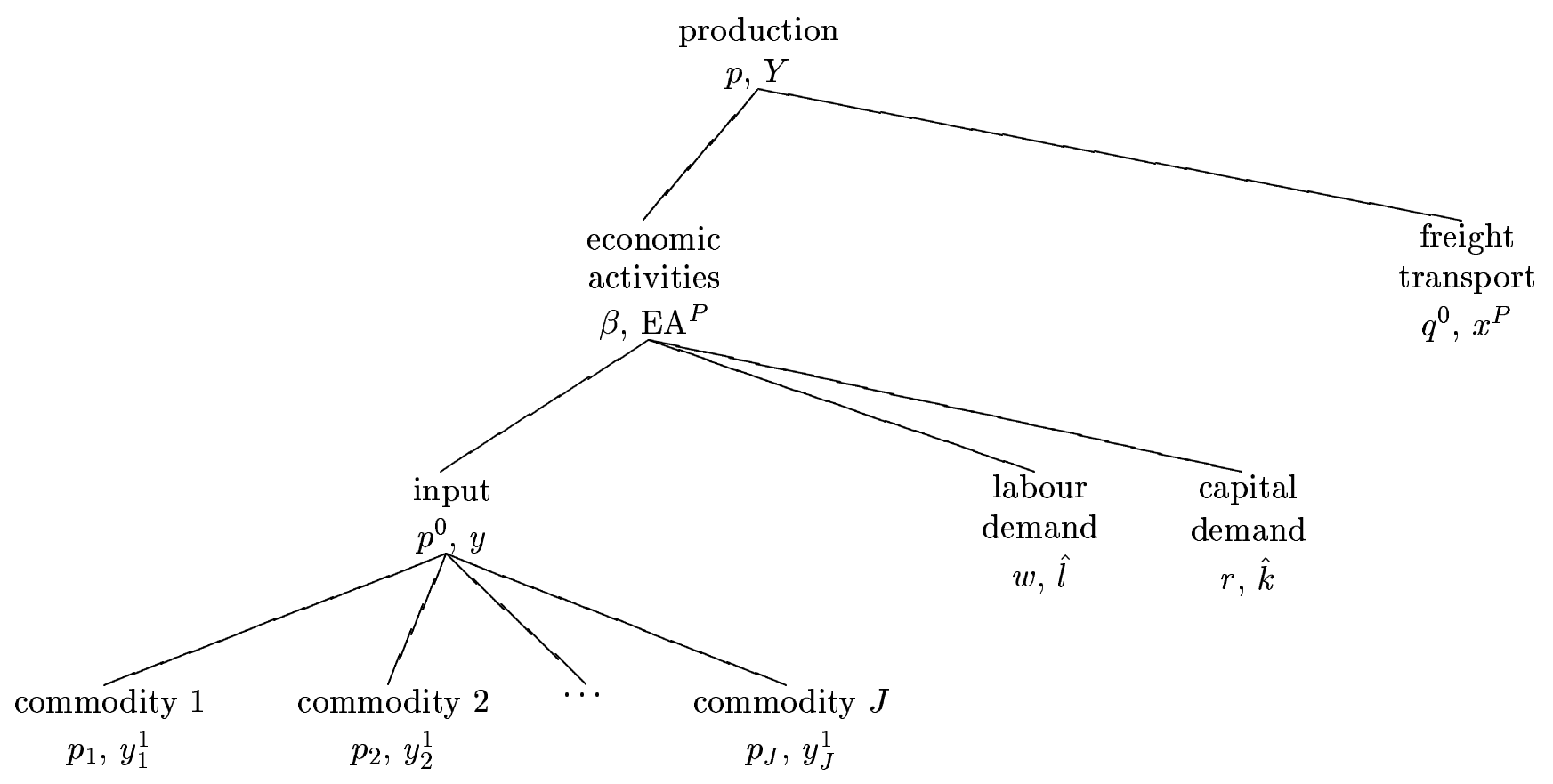

FIgURE 4: The production tree $\mathcal{P}$ of a producer, where each node provides the cost minimizing amount of each good, and its price.

We define a mapping of share parameters over the production tree $\mathcal{P}$, given by $\gamma^{P}: A_{\mathcal{P}} \rightarrow$ $[0,1]^{\left|A_{\mathcal{P}}\right|}$. The producer is assumed to maximize profits which, under the constant returns to scale assumption, reduces to the following problem of minimizing its costs,

$$
\begin{array}{ll}
c^{1}\left(\beta, q^{0} ; Y\right)=\min _{\mathrm{EA}^{P}, x^{P, 0}} & \beta_{j} \mathrm{EA}^{P}+q^{0} x^{P, 0} \\
\text { s.t. } & Y_{j}=\min \left\{\frac{\mathrm{EA}^{P}}{\gamma_{1}^{P, 1}}, \frac{x^{P, 0}}{\gamma_{2}^{P, 1}}\right\} \\
& \mathrm{EA}^{P} \geq 0, x^{P, 0} \geq 0 .
\end{array}
$$

Solving this minimization problem results in the optimal economic activities of the producer and the necessary amount of transport to produce $Y$ units of the output commodity of the producer in the first layer of $\mathcal{P}$.

Similarly to the consumer, freight transport $x^{P}$ is given by a mapping over the transport tree $\mathcal{T}$ which is taken as a subtree of $\mathcal{P}$ with $x^{P, 0}$ as its root. The producer chooses among the transport alternatives available to him on any layer $k$ of the transport tree $\mathcal{T}$ a combination that minimizes his costs, according to the following optimization problem,

$$
\begin{array}{lll}
c^{k}\left(q^{k} ; x^{P, 0}\right)= & \min _{x^{P, k}} & \sum_{w_{\mathcal{T}}^{k} \in W_{\mathcal{T}}} q_{w_{\mathcal{T}}^{k}}^{k} x_{w_{\mathcal{T}}^{k}}^{P, k} \\
& \text { s.t. } & x^{P, 0}=\left(\sum_{w_{\mathcal{T}}^{k} \in W_{\mathcal{T}}}\left(x_{w_{\mathcal{T}}^{k}}^{P, k}\right)^{\rho^{k}}\right)^{\frac{1}{\rho^{k}}} .
\end{array}
$$


The economic activities of the producer consist of demanding the primary inputs labour and capital, and of an aggregate input commodity. In layer 2 of $\mathcal{P}$, the cost minimizing amounts of these inputs follow from the minimization problem,

$$
\begin{array}{ll}
\min _{\hat{l}, \hat{k}, y} & w \hat{l}+r \hat{k}+p^{0} y \\
\text { s.t. } & \operatorname{EA}^{P}=\left(\gamma_{11}^{P, 2} y^{\frac{\delta_{2}^{P}-1}{\delta_{2}^{P}}}+\gamma_{12}^{P, 2} \hat{l}_{\frac{\delta_{2}^{P}-1}{\delta_{2}^{P}}}^{P}+\gamma_{13}^{P, 2} \hat{k}^{\frac{\delta_{2}^{P}-1}{\delta_{2}^{P}}}\right)^{\frac{\delta_{2}^{P}}{\delta_{2}^{P}-1}} \\
& \hat{l} \geq 0, \hat{k} \geq 0, y \geq 0,
\end{array}
$$

where we chose a constant elasticity of substitution function with substitution elasticity $\delta_{2}^{P}$ between the input goods, to produce the output good.

Similarly, the aggregate input commodity is produced according to a constant elasticity of substitution production function with substitution elasticity $\delta_{3}^{P}$ among the commodities of each region, which results in the following cost minimization problem

$$
\begin{array}{ll}
\min _{y^{1}(1), \ldots, y^{1}(J)} & \sum_{h=1}^{J} p_{h} y^{1}(h) \\
\text { s.t. } & y=\left(\sum_{h=1}^{J} \gamma_{11 h}^{P, 3} y^{1}(h)^{\frac{\delta_{3}^{P}-1}{\delta_{3}^{P}}}\right)^{\frac{\delta_{2}^{P}}{\delta_{2}^{P}-1}} \\
& y^{1}(1) \geq 0, \ldots, y^{1}(J) \geq 0,
\end{array}
$$

to provide the optimal input amounts.

Also freight transport $x^{P}$ is given by a mapping over the transport tree $\mathcal{T}$ which, similarly to $\mathcal{C}$, is taken as a subtree of $\mathcal{P}$ with $x^{P, 0}$ as its root. The share mapping $\gamma^{P}$ is extended over $\mathcal{T}$. In the case we use discrete choice analysis to study freight transport choice, we can calculate the mode choice probabilities $\pi_{w_{\mathcal{T}}^{k}}^{P}\left(q_{w_{\mathcal{T}}^{k}}^{k} ; q^{0} x^{P .0}, A_{w_{\mathcal{T}}^{k}}\right)$ similar to $\pi^{C}$ with respect to the consumer problem, using a multinomial logit function.

The above framework encapsulates the various empirical elasticity studies in the transport sector as special cases. The advantage of this approach is a comprehensive and consistent mapping of all economic forces at work in the transport sector. This approach may also offer a more rigorous basis for the specification of price elasticity studies of transport demand, which are often estimated on an ad hoc basis. In the next section, we will address more specifically the nature of various elasticity studies within the framework introduced in this section. 


\section{Common Characteristics of Price Elasticity Studies of Transport Demand}

In the previous section we distinguished between passenger transport and freight transport demand. Passenger transport demand results from the consumption tree $\mathcal{C}$ while freight transport demand results from the production tree $\mathcal{P}$. Utility maximization c.q. cost minimization then result in optimal amounts of passenger transport demand $x_{w_{\mathcal{T}}}^{C}\left(\beta, q ; M, A_{w_{\mathcal{T}}}\right)$ and freight demand $x_{w_{\mathcal{T}}}^{P}\left(\beta, q ; A_{w_{\mathcal{T}}}\right)$ for each transport alternative $w_{\mathcal{T}}$. The own price elasticity of passenger (freight) demand for a transport alternative $w_{\mathcal{T}}$ is defined as the percentage change in passenger (freight) demand, $x_{w_{\mathcal{T}}}^{C}\left(x_{w_{\mathcal{T}}}^{P}\right)$, resulting from a one percent change in its price $q_{w_{\mathcal{T}}}$. In order to estimate such a price elasticity, we use the studies listed in Table 1. These studies provide estimates for price elasticities based on different values of study characteristics. We use these price elasticity estimates and study characteristics in the following statistical model,

$$
\sigma=\sum_{v_{1} \in \mathcal{I}_{1}} \mu_{v_{1}} F_{v_{1}}+\sum_{v_{2} \in \mathcal{I}_{2}} \lambda_{v_{2}} D_{v_{2}}+\sum_{v_{3} \in \mathcal{I}_{3}} \bar{\sigma}_{v_{3}} G_{v_{3}}+\xi
$$

where $\xi$ denotes the disturbance term. Furthermore (3) distinguishes among three types of study characteristics, namely model characteristics denoted by $G_{v_{3}}, v_{3} \in \mathcal{I}_{3}$, modal characteristics denoted by $F_{v_{2}}, v_{2} \in \mathcal{I}_{2}$, and data characteristics denoted by $D_{v_{1}}, v_{1} \in \mathcal{I}_{1}$.

The model characteristics $G_{v_{3}}, v_{3} \in \mathcal{I}_{3}$, refer to the often very different models and their specification that underly studies of own-price elasticities of transport demand in a metaanalysis. Table 1 provides an overview of the studies in our meta-analysis according to these model characteristics. It shows a distinction among mainly micro-econometric models, micro-economic models, and discrete choice models. Micro-econometric models as used in Rus (1990) and Owen and Phillips (1987) use an econometric model to estimate transport demand directly from its characteristics. These characteristics mainly consist of the prices

$q_{w_{\mathcal{T}}^{k}}$ and elements of the set of characteristics $A_{w_{\mathcal{T}}^{k}}$ of the competing transport alternatives $w_{\mathcal{T}}^{k}$. The specification of the micro-econometric models in Table 1 can all be obtained by imposing specific conditions on the parameters in a double-log specification of $x_{w_{\mathcal{T}}^{k}}^{C}$ or $x_{w_{\mathcal{T}}^{k}}^{P}$.

Micro-econometric models do not assume any particular behaviour to underly passenger and freight demand, contrary to micro-economic models which are more comparable to our framework, where passenger demand is assumed to be the result of the utility maximizing behaviour of the consumer and freight demand the result of the cost minimizing behaviour of the producer. Friedlaender and Spady (1980) and Taplin (1997) among others use such models to estimate passenger or freight transport demand via the well-known Shepherd's Lemma 
with respect to the producer's cost function or its equivalent with respect to the consumer's expenditure function.

\begin{tabular}{|c|c|c|}
\hline PUBLICATION & TRANSPORT DEMAND MODEL & FUNCTIONAL FORMS \\
\hline Abdelwahab (1998) & simultaneous equations & linear demand and mode choice \\
\hline Abrahams (1983) & micro-econometric & linear \\
\hline Alperovich and Machines (1994) & micro-econometric & double $\log$ \\
\hline Anas and Moses (1984) & discrete choice & linear additive random utility \\
\hline Bhat (1995) & discrete choice & linear additive random utility \\
\hline Friedlaender and Spady (1980) & micro-economic & $\begin{array}{l}\text { translog cost function } \\
\text { trat }\end{array}$ \\
\hline Fridstroöm and Thune-Larsen (1989) & micro-econometric & double log \\
\hline Gilbert and Jalilian (1991) & micro-econometric & double log \\
\hline Henscher (1998) & discrete choice & linear additive random utility \\
\hline Ippolito (1981) & micro-econometric & double log \\
\hline Jung and Fuji (1976) & micro-economic & translog expenditure \\
\hline Kyte, Stoner, and Cryer (1988) & micro-econometric & transfer function \\
\hline Lewis and Widup (1982) & partial equilibrium & translog demand and supply \\
\hline Mannering (1986) & micro-econometric & linear \\
\hline McCarthy (1997) & discrete choice & $\begin{array}{l}\text { linear additive random utility } \\
\text { linear logit }\end{array}$ \\
\hline Oum (1989) & micro-economic & translog demand \\
\hline Oum and Gillen (1983) & micro-economic & translog cost \\
\hline Owen and Phillips (1987) & micro-econometric & double log \\
\hline Rus (1990) & micro-econometric & double log \\
\hline Selvanathan and Selvanathan (1994) & micro-economic & translog expenditure function \\
\hline Spady and Friedlaender (1979) & micro-economic & translog cost \\
\hline Strazheim (1978) & micro-econometric & double log \\
\hline Taplin (1997) & micro-economic & translog expenditure \\
\hline Wardman, Toner, and Whelan (1997) & discrete choice & $\begin{array}{l}\text { linear additive random utility } \\
\text { multinomial logit }\end{array}$ \\
\hline Wilson, Wilson, and Koo (1988) & partial equilibrium & $\begin{array}{l}\text { linear demand } \\
\text { linear supply }\end{array}$ \\
\hline
\end{tabular}

TABLE 1: Description of studies according to model characteristics:

Type of transport demand model and functional forms.

Transport demand as modelled in micro-economic models can be decomposed according to $x_{w_{\mathcal{T}}^{k}}^{C}\left(\beta, q ; M, A_{w_{\mathcal{T}}^{k}}\right)=\pi_{w_{\mathcal{T}}^{k}}^{C}\left(q ; A_{w_{\mathcal{T}}^{k}}\right) x^{C, 0}\left(\beta, q^{0} ; M\right)$ where the volume component $x^{C, 0}\left(\beta, q^{0} ; M\right)$ denotes the total amount of transport necessary for the consumer to maximize his utility and the mode choice component $\pi_{w_{\mathcal{T}}^{k}}^{C}\left(q ; A_{w_{\mathcal{T}}^{k}}\right)$ denotes the share of this volume component allocated to transport mode $w_{\mathcal{T}}^{k}$. Similarly we can decompose freight demand $x_{w_{\mathcal{T}}^{k}}^{P}\left(\beta, q ; M, A_{w_{\mathcal{T}}^{k}}\right)$ into a mode-choice component $\pi_{w_{\mathcal{T}}^{k}}^{F}\left(q ; A_{w_{\mathcal{T}}^{k}}\right)$ and a volume component $x^{P, 0}\left(\beta, q^{0}\right)$. Discrete choice models concentrate on the estimation of the mode-choice components and therefore require a specification of the probability density functions $\pi^{C}$ and $\pi^{P}$. The discrete choice models in Table 1 all use a special case of a multinomial logit model, i.e. they use a multinomial logit model or they use a model that can be derived by imposing extra conditions on the multinomial logit model. 
It follows that we can distinguish three different models in Table 1, each of them with their own functional specification. We refer to micro-econometric models as a model of type 1 , micro-economic models as a model of type 2. and discrete choice models as a model of type 3. Notice that a set of models where we can distinguish say two different functional specifications would be split up into two different types. Apart from these three dominant model types, Abdelwahab (1998) and among others Wilson, Wilson, and Koo (1988) provide different model types such as simultaneous equations and a partial equilibrium model, which we denote with model types 4 and 5 respectively. Hence the set $\mathcal{I}_{3}$ of model types equals $\{1, \ldots, 5\}$. In (3) we have therefore defined the dummies $G_{v_{3}}$ for $v_{3} \in \mathcal{I}_{3}$, where $G_{v_{3}}=1$ if a study uses a model of type $v_{3}$ and $G_{v_{3}}=0$ otherwise. The variable $\bar{\sigma}_{v_{3}}$ for each model type $v_{3}$ then provides an indication of the impact of the model and its specification on the estimation of own price elasticities. It says nothing on for example the transport type it refers to, nor to the influence of the underlying data characteristics. The particular elasticity characteristics and data characteristics explain the deviation of each study's elasticity estimate from the estimate $\bar{\sigma}_{v_{3}}$ based on model $v_{3}$ and its specification.

The modality characteristics in (3) refer to the transport alternatives $w_{\mathcal{T}}^{k}$ considered in each studies. This choice then also determines the exact argument of the transport demand functions. We have incorporated the modality characteristics into our meta analysis in (3) through the introduction of dummy vectors $F_{v_{1}}$. Modality characteristics are given by the aggregation levels of transport, the elasticity concept used in the studies, and whether the study refers to passenger or freight transport. The aggregation levels of transport refer to the levels in the transport tree $\mathcal{T}$, where transport at the top node is the most aggregate level, and transport by rail, road, or air the most disaggregate levels. In between these extremes, the transport tree $\mathcal{T}$ distinguishes aggregation into farecard and ordinary fare transport, and in price setting and price taking. We define the dummies $F_{\mathrm{SET} / \mathrm{TAK}}$ and $F_{\mathrm{OF} / \mathrm{FC}}$ corresponding to these disaggregation levels as follows,

$$
\begin{aligned}
& F_{\mathrm{SET} / \mathrm{TAK}}=1 \text { if the aggregation level refers to price-setting, } \\
& \text { and } F_{\mathrm{SET} / \mathrm{TAK}}=0 \text { if it refers to price taking. } \\
& F_{\mathrm{OF} / \mathrm{FC}}=1 \text { if the aggregation level refers to ordinary fare pricing, } \\
& \text { and } F_{\mathrm{OF} / \mathrm{FC}}=0 \text { if it refers to farecard pricing, }
\end{aligned}
$$

and, the dummy columns $F_{\mathrm{ROAD}}, F_{\mathrm{AIR}}$, and $F_{\mathrm{RAIL}}$ that refer to the most disaggregate levels in $\mathcal{T}$ as follows, 


$$
\begin{aligned}
& F_{\mathrm{ROAD}}=1 \text { if the study considers road transport, } \\
& \text { and } D_{\mathrm{ROAD}}=0 \text { otherwise, } \\
& F_{\mathrm{AIR}}=1 \text { if the study considers air transport, } \\
& \text { and } D_{\mathrm{AIR}}=0 \text { otherwise, } \\
& F_{\mathrm{RAIL}}=1 \text { if the study considers rail transport, } \\
& \text { and } D_{\mathrm{RAIL}}=0 \text { otherwise. }
\end{aligned}
$$

Oum, Waters II, and Yong (1992) make a distinction between ordinary price elasticities on the one hand, and so-called mode-choice elasticities on the other hand. Mode-choice elasticities only refer to changes in the shares $\pi_{w_{\mathcal{T}}^{k}}^{C}\left(q ; A_{w_{\mathcal{T}}^{k}}\right)$ and $\pi_{w_{\mathcal{T}}^{k}}^{P}\left(q ; A_{w_{\mathcal{T}}^{k}}\right)$, of a fixed volume of traffic among modes, and do not take account of the effect of a price change on the aggregate volume of traffic. The use of discrete choice models mainly results in mode choice elasticities. Ordinary price elasticities on the other hand do take account of this change in aggregate volume. Following studies on mode-choice elasticities such as Henscher (1998), we use the name direct choice elasticity for the mode-choice equivalent of the own-price elasticity. We define the dummy variable $D_{\mathrm{Op} / \mathrm{Ds}}=1$ if a study considers own-price elasticities, and $D_{\mathrm{Op} / \mathrm{Ds}}=0$ if a study considers direct share elasticities.

The demand for transport by the agents in an economy results from their behaviour described in the consumption tree $\mathcal{C}$ and production tree $\mathcal{P}$. Transport demand that results from $\mathcal{C}$ is referred to as passenger transport, and transport demand that results from $\mathcal{P}$ is referred to as freight transport demand. In (3), we have therefore included the dummy $F_{\mathrm{PAS} / \mathrm{Fr}}$ whose components are equal to one if the study refers to passenger transport $x^{C}$ and zero if the study refers to freight transport $x^{P}$. Concluding we take the set $\mathcal{I}_{1}$ equal to $\{\mathrm{SET} / \mathrm{TAK}$, Of/Fc, RoAd, Air, Rail, Op/Ds, Cp/Cs, Pas/Fr \}.

The data characteristics in (3) are given by the dummies $D_{v_{2}}$, for $v_{2} \in \mathcal{I}_{2}$ where the set $\mathcal{I}_{2}$ equals $\{\mathrm{LT} / \mathrm{ST}, \mathrm{UR} / \mathrm{NAT}, \mathrm{SP} / \mathrm{RP}, \mathrm{TS} / \mathrm{CS}\}$, which refer to the following characteristics. The time horizon to whether the study considers the estimation of a long term (LT) or short term $(\mathrm{ST})$ price elasticity. So we define a dummy $D_{\mathrm{LT} / \mathrm{St}}$ which equals zero when referring to the short term one when referring to the long term. The geographical scale refers to the type of the region considered in each study. The type of a region may vary from studies on an urban scale to studies that consider transport on a nation-wide scale. The urban scale refers to the use of the available transport modes for relatively short distances, while the national scale also refers to longer distances. We define a dummy $D_{\text {Ur/NAT }}$ in (3) such that $D_{\mathrm{UR} / \mathrm{NAT}}=1$ when referring to the national scale and $D_{\mathrm{UR} / \mathrm{NAT}}=0$ when referring to the urban scale. With respect to the type of data, Nijkamp and Pepping (1998) distinguish crosssection, time series, panel, and stated or revealed preference data. The data used in a study 
influence the estimation of an elasticity. Elasticities based on cross-section data are often higher than elasticities based on time-series data. Elasticities based on stated preference data are higher than cross-section data, unless they are rescaled. This characteristic defines two dummies, namely $D_{\mathrm{SP} / \mathrm{RP}}$ such that $D_{\mathrm{SP} / \mathrm{RP}}=1$ when a study uses stated preference data and $D_{\mathrm{SP} / \mathrm{RP}}=0$ when a study uses revealed preference data, and $D_{\mathrm{Ts} / \mathrm{Cs}}$ such that $D_{\mathrm{Ts} / \mathrm{Cs}}=1$ when a study uses time series data and $D_{\mathrm{Ts} / \mathrm{Cs}}=0$ when cross-section data.

The above systematic description of the various attributes of the transport demand elasticity studies offers a useful input for an empirical meta-analytical experiment, in which the estimation is based on the meta-regression model in (3).

\section{A Meta-Analysis}

A meta-analysis of price-elasticities of transport demand tries to explain the estimate of such an elasticity from various characteristics. The previous section distinguished among data, model, and modal characteristics. While the data and model characteristics were obtained from the various studies that underly our meta-analysis, the modal characteristics are derived from the encapsulating general equilibrium model introduced in Section 2. The model characteristics of any particular study provide this study's specification of transport demand in the encapsulating general equilibrium model. Equation (3) links the estimation of a price elasticity with dummy variables that refer to these characteristics.

In order to be able to estimate a dummy model, we have to choose a reference. With respect to (3), we take road transport as our reference modal characteristic, and the specification of transport demand using a micro-econometric model as our reference model characteristic. In order to implement this, we replace (3) with the regression equation,

$$
\sigma=\text { constant } E+\sum_{v_{1}: v_{1} \neq \mathrm{ROAD}} \mu_{v_{1}} F_{v_{1}}+\sum_{v_{2}} \lambda_{v_{2}} D_{v_{2}}+\sum_{v_{3}: v_{3} \neq 1} \bar{\sigma}_{v_{3}} G_{v_{3}}+\xi
$$

where $E$ denotes a vector with all components equal to one, and $\xi$ denotes the error term in the estimation. Estimating this regression equation provides us with estimates for all the variables in (4). The estimate constant gives the estimate for a price elasticity of road transport using a micro-econometric model to specify the demand model. The estimates of the other variables are interpreted as deviations from the estimate for constant, i.e. the reference, caused by the particular study characteristic associated with the dummy variable. Given the definitions of the different dummy variables in Section 2, the reference value also refers to 
price taking, farecard, urban freight transport based on cross-section, revealed preference data. The estimated price elasticity of transport demand, based on the constant alone is a short-term, direct share, price elasticity.

Each study in Table 1 of the previous section provides estimates for a price elasticity of transport demand $\sigma$ and values for the characteristics represented by the dummies in (4). We use these data to estimate (4). If we assume that the error term $\xi$ is identically and independently distributed according to a standard normal distribution, we can estimate (4) using the ordinary least squares (OLS) method. The results of this estimation can be found in Table 2 .

\begin{tabular}{|l|rrrr|}
\hline \hline Variable & Coefficient & Std. Error & t-Statistic & Prob. \\
\hline \hline constant & -1.353324 & 0.475050 & -2.848804 & 0.0060 \\
$\bar{\sigma}_{2}$ & -0.714582 & 0.265275 & -2.693742 & 0.0091 \\
$\bar{\sigma}_{3}$ & -0.384396 & 0.470790 & -0.816492 & 0.4175 \\
$\bar{\sigma}_{4}$ & -0.933139 & 0.609006 & -1.532232 & 0.1306 \\
$\bar{\sigma}_{5}$ & -0.004699 & 0.453297 & 0.010366 & 0.9918 \\
$\mu_{\mathrm{AIR}}$ & -0.674762 & 0.258875 & -2.606517 & 0.0115 \\
$\mu_{\mathrm{RAIL}}$ & -0.198073 & 0.185952 & -1.065188 & 0.2910 \\
$\mu_{\mathrm{PAS} / \mathrm{FR}}$ & 0.374900 & 0.354000 & 1.059038 & 0.2938 \\
$\mu_{\mathrm{SET} / \mathrm{TAK}}$ & 0.192884 & 0.273805 & 0.704456 & 0.4838 \\
$\mu_{\mathrm{OF} / \mathrm{FC}}$ & 0.120075 & 0.255364 & 0.470211 & 0.6399 \\
$\lambda_{\mathrm{UR} / \mathrm{NAT}}$ & 0.693930 & 0.254332 & 2.728441 & 0.0083 \\
$\lambda_{\mathrm{LT} / \mathrm{ST}}$ & -0.299366 & 0.258996 & -1.155870 & 0.2522 \\
$\lambda_{\mathrm{SP} / \mathrm{RP}}$ & -0.280138 & 0.218259 & -1.283516 & 0.2042 \\
$\lambda_{\mathrm{TS} / \mathrm{Cs}}$ & -0.286783 & 0.290886 & -0.985896 & 0.3281 \\
$\lambda_{\mathrm{OP} / \mathrm{Ds}}$ & 0.083355 & 0.386452 & 0.215693 & 0.8299 \\
\hline \hline
\end{tabular}

\begin{tabular}{|lr|lr|}
\hline \hline R-squared & 0.403345 & Mean dependent var & -0.956845 \\
Adjusted R-squared & 0.266408 & S.D. dependent var & 0.734986 \\
S.E. of regression & 0.629516 & Akaike info criterion & 2.087145 \\
Sum squared resid & 24.17369 & Schwarz criterion & 2.547159 \\
Log likelihood & -64.31153 & & \\
\hline \hline
\end{tabular}

Table 2: The estimation results of applying OLS on (4).

The estimates for the variables in Table 2 are significantly different from zero at the five percent level, if the associated t-value is larger than 2 in absolute value. We see that the 
estimates for constant, and for the dummy variables associated with the study characteristics that refer to the geographical scale of the data, air transport, and the use of a micro-economic model are significantly different from zero at the five percent level. When we allow for a twenty percent significance level then the associated t-value should be larger than 1.28. At this level also the study characteristics referring to the use of stated or revealed preference data, and the use of a simultaneous equations model as in Abdelwahab (1998) become significantly different from zero.

The estimate of the constant in (4) gives us a reference value that refers to an estimate of a price elasticity with the aforementioned type of transport. The estimates for the dummy variables represent a possibly significant deviation from this reference value. The reference value constant refers among others to an estimate of a price elasticity based on a micro-econometric model for freight transport, $x_{w_{\mathcal{T}}^{k}}^{P}\left(q_{w_{\mathcal{T}}^{k}} ; A_{w_{\mathcal{T}}^{k}}\right)$. The estimation results in Table 2 indicate that replacing the micro-econometric model with a micro-economic model results in a significantly lower estimate for the price elasticity. Transport demand based on a micro-economic model turns out to be significantly more price elastic than when based on a micro-econometric model. Micro-economic models assume that the producer's behaviour can be described as cost minimization which results in a freight transport demand function $x_{w_{\mathcal{T}}^{k}}^{P}\left(\beta, q_{w_{\mathcal{T}}^{k}} ; A_{w_{\mathcal{T}}^{k}}\right)$, which also accounts for the influence of the producer's economic activities. Micro-economic studies like Friedlaender and Spady (1980) mention the importance of the economic activities of the producer on the determination of the price elasticity of freight transport demand. Taplin (1997) for example shows this with respect to passenger transport demand. Our estimation results confirm the importance of inclusion of the economic activities into the underlying transport demand model.

Discrete choice models do not seem to have a significantly different impact on the estimation of a price elasticity of transport compared to the use of micro-econometric models. Notice that discrete choice models derive the mode choice elasticity from the probability of the producer chosing transport alternative $w_{\mathcal{T}}^{k}, \pi_{w_{\mathcal{T}}^{k}}^{P}\left(q ; A_{w_{\mathcal{T}}^{k}}\right)$, and therefore assume a constant volume of transport to be allocated among the various available modes. The insignificance of changing between discrete choice models and micro-econometric models might suggest that micro-econometric models fail to take account of the impact on the volume of transport due to price changes. In contrast, switching to a micro-economic model for the estimation of a price elasticity of transport results in a significantly more elastic transport demand. This could be an indication of the impact of price changes on the volume of transport demand.

With respect to modal characteristics, we see that Table 2 provides an estimate of -0.67 when transport demand refers to transport by air and of -0.20 when transport demand refers to rail transport instead of road transport. We would therefore obtain an estimate of -2.03 for air transport demand and of -1.55 for rail transport. Contrary to rail transport demand, 
the price elasticity of air transport demand is estimated as significantly more elastic with respect to changes in its own price than road transport demand. A change in the own price of road transport therefore results in a decrease in road transport demand that is lower than the decrease in air travel demand. This sounds plausible as air transport demand mostly refers to leisure travel, as is confirmed by the underlying studies in for example Taplin (1997). Rail transport demand shows a price elasticity estimate that is not significantly different from the reference elasticity value. Hence the same comparison can be made between air and rail transport demand.

The reference value represented by the estimate for the constant in (4) refers to urban transport demand. The estimate of $\lambda_{\mathrm{UR} / \mathrm{NAT}_{\mathrm{A}}}$ equal to 0.69 shows a significantly less elastic transport demand on national scale, -0.66 , than transport demand on urban scale as referred to by the referencevalue. The urban level allows for much more possibilities to change to another means of transport in case of a price rise. One can even choose to walk, something which is more difficult when transport on a national scale is considered. This makes a lower elastic transport demand on the national scale plausible.

The data underlying the reference value are characterized by revealed preference. This means that the data are the actual volume of transport. Contrary to the amounts of transport that are said to be demanded when travellers are asked in interviews. This last type of data refers to stated preference. Table 2 provides an estimate of $\lambda_{\mathrm{SP} / \mathrm{RP}}$ equal to -0.28 which indicates that the use of stated preference instead of revealed preference to obtain data on transport demand results in a lower estimate of its price elasticity than the reference value. This may indicate the existence of a certain 'exaggeration-factor' in transport demand when asked to a traveller. This means that, when asked about his travel choices, the traveller indicates that he will quicker lower his demand for transport than he will actually do when confronted with a real price rise. The use of stated preference data instead of revealed preference data is of less influence on the estimate of a price elasticity of transport demand than the use of national instead of urban transport data.

\section{Conclusions and Points of Further Research}

Meta-analysis is currently a popular tool and field of research in experimental sciences such as medicine or psychology, but it hasn't fully reached the economic sciences yet. This is not so strange considering the fact that in order to successfully apply meta-analytic methods, the underlying studies are assumed to be comparable. Due to the underlying ceteris-paribus condition in many economic studies, this assumption turns out to be violated in economics.

In this paper we have considered a meta-analysis of price elasticities of transport demand 
in order to start up research for the possible application of meta-analytic techniques in the economic sciences. The estimation of such price elasticities is characterized by the use of very different underlying models of transport demand. This paper distinguished among microeconometric, micro-economic, and discrete choice models as often applied models on this area. We have constructed a general equilibrium framework that encapsulates all the models used in the studies that underly our meta-analysis. As such the general equilibrium framework makes all these studies comparable. From this common reference framework, we have derived the modal characteristics which have different values for each study. Together with the data characteristics underlying each study and the model characteristics, these modal characteristics created a meta-regression equation to estimate the price elasticities of transport demand.

It turns out that especially the use of a micro-economic model instead of the reference micro-econometric model has a significant influence on the estimation of a price elasticity. Micro-economic models as used in for example Friedlaender and Spady (1980) explicitly regard transport as a demand derived from the economic activities of the consumer or producer. These models are much closer to the general equilibrium framework introduced in Section 2 than the other two dominant model types. Micro-economic models not only cover most of the economic factors that are essential to the determination of transport demand but it also incorporates the economic interactions. Discrete choice models only consider mode choice, and therefore disregard the impact on the volume of transport. Micro-econometric models only provide a reduced form equation relating transport demand to a number of characteristics, but leave out their economic interactions. This results into a significantly more elastic price elasticity when applying micro-economic models.

Air transport forms a significant modal characteristic. Air transport demand turns out to be more sensitive to price changes than the other modes of transport, i.e. rail and road, considered in our meta-analysis. This may be due to the different types of economic activities associated with each type of transport. In view of the previous discussion with respect to the use of models, this dependency on the consumer's or producer's economic activities suggests a preference for micro-economic models as the most appropriate type of model to underly the estimation of a price elasticity.

The meta regression results show that it differs significantly for the estimation of a price elasticity of transport demand whether the data are obtained from transport demand on an urban scale or on a national scale. Using transport demand on an urban scale results in a lower estimate of the price elasticity. This seems to be a result from the availability alternatives. On an urban scale the consumer or producer has more alternatives to choose from than on the national scale, which makes him change quicker in response to price changes. 


\section{References}

Abdelwahab, W. (1998). Elasticities of mode choice probabilities and market elasticities of demand: Evidence from a simultaneous mode choice/shipment-size freight transport model. Transportation Research E (Logistics and Transportation Review) 34 (4), 257-266.

Abrahams, M. (1983). A service quality model for air travel demand: An empirical study. Transportation Research 17A(5), 385-393.

Alperovich, G. and Y. Machines (1994). The role of wealth in the demand for international air travel. Journal of Transport Economics and Policy 28(2), 163-173.

Anas, A. and L. Moses (1984). Qualitative choice and the blending of discrete alternatives. The Review of Economics and Statistics 66 (4), 547-555.

Bal, F. and P. Nijkamp (1999). The ceteris paribus clause in the context of meta-analysis and value transfer. In P. N. R. Florax and K. Willis (Eds.), Comparative Environmental Economic Assessment, London. Edward Elgar.

Bhat, C. (1995). A heteroscedastic extreme value model of intercity travel mode choice. Transportation Research B 29(6), 471-483.

Fridstroöm, L. and H. Thune-Larsen (1989). An econometric air travel demand model for the entire conventional domestic network: The case of Norway. Transportation Research 23B(3), 213-224.

Friedlaender, A. and R. Spady (1980). A derived demand function for freight transportation. The Review of Economics and Statistics 62, 432-441.

Gilbert, C. and H. Jalilian (1991). The demand for travel and for travelcards on London regional transport. Journal of Transport Economics and Policy 25, 3-29.

Haitovsky, Y., I. Salomon, and A. Silman (1987). The economic impact of charter flights on tourism to Israel: An econometric approach. Journal of Transport Economics and Policy 21 (2), 111-134.

Henscher, D. (1998). Establishing a fare elasticity regime for urban passenger transport. Journal of Transport Economics and Policy 32 (2), 221-246.

Ippolito, R. (1981). Estimating airline demand with quality of service variables. Journal of Transport Economics and Policy 15(1), 7-16.

Jung, J. and E. Fuji (1976). The price elasticity of demand for air travel. Journal of Transport Economics and Policy 10, 257-262.

Kremers, H., P. Nijkamp, and P. Rietveld (1999). The scope of meta-analysis for transport impact policy analysis in environmental economics. In P. N. R. Florax and K. Willis (Eds.), Comparative Environmental Economic Assessment, London. Edward Elgar.

Kyte, M., J. Stoner, and J. Cryer (1988). A time-series analysis of public transport ridership in Portland, Oregon. Transportation Research 22A(5), 345-359.

Lewis, K. and D. Widup (1982). Deregulation and rail-truck competition: Evidence from a translog transport demand model for assembled automobiles. Journal of Transport Economics and Policy 16(2), 139-149. 
Mannering, F. (1986). A note on endogenous variables in household vehicle utilisation equations. Transportation Research 20B(1), 1-6.

McCarthy, P. (1997). The role of captivity in aggregate share models of intercity passenger travel. Journal of Transport Economics and Policy 31(3), 293-308.

Nijkamp, P. and G. Pepping (1998). Meta-analysis for explaining the variance in public transport demand elasticities in Europe. Journal of Transportation and Statistics 1, $1-14$.

Oum, T. (1989). Alternative demand models and their elasticity estimates. Journal of Transport Economics and Policy 23(2), 163-187.

Oum, T. and D. Gillen (1983). The structure of intercity travel demands in Canada: Theory tests and empirical results. Transportation Research 17B(3), 175-191.

Oum, T., W. Waters II, and J. Yong (1992). Concepts of price elasticities of transport demand and recent empirical estimates. an interpretative survey. Journal of Transport Economics and Policy 26, 139-154.

Owen, A. and G. Phillips (1987). The characteristics of railway passenger demand. an econometric investigation. Journal of Transport Economics and Policy 21 (3), 231-253.

Rus, G. (1990). Public transport demand elasticities in Spain. Journal of Transport Economics and Policy 24, 189-201.

Selvanathan, E. and S. Selvanathan (1994). The demand for transport and communication in the United Kingdom and Australia. Transportation Research 28B(1), 1-9.

Spady, R. and A. Friedlaender (1979). Hedonic cost functions for the regulated trucking industry. The Bell Journal of Economics 9(1), 159-179.

Strazheim, M. (1978). Airline demand functions in the north atlantic and their pricing implications. Journal of Transport Economics and Policy 12, 179-195.

Taplin, J. (1997). A generalized decomposition of travel-related demand elasticities into choice and generation components. Journal of Transport Economics and Policy 31(2), 183-191.

Wardman, M., J. Toner, and G. Whelan (1997). Interactions between rail and car in the inter-urban leisure travel market in Great-Britain. Journal of Transport Economics and Policy 31 (2), 163-182.

Wilson, W., W. Wilson, and W. Koo (1988). Modal competition in grain transport. Journal of Transport Economics and Policy 23(3), 319-337. 


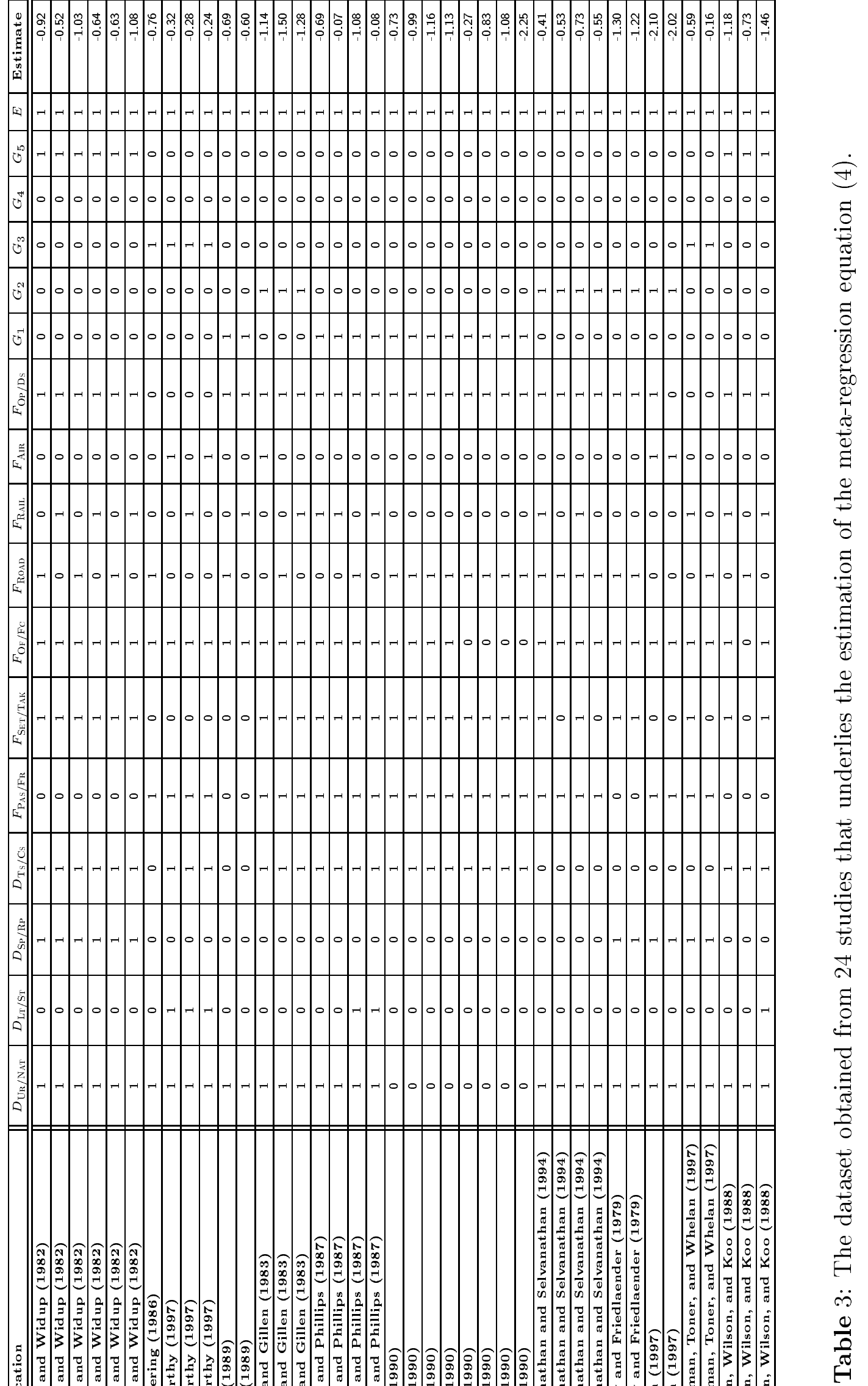

